
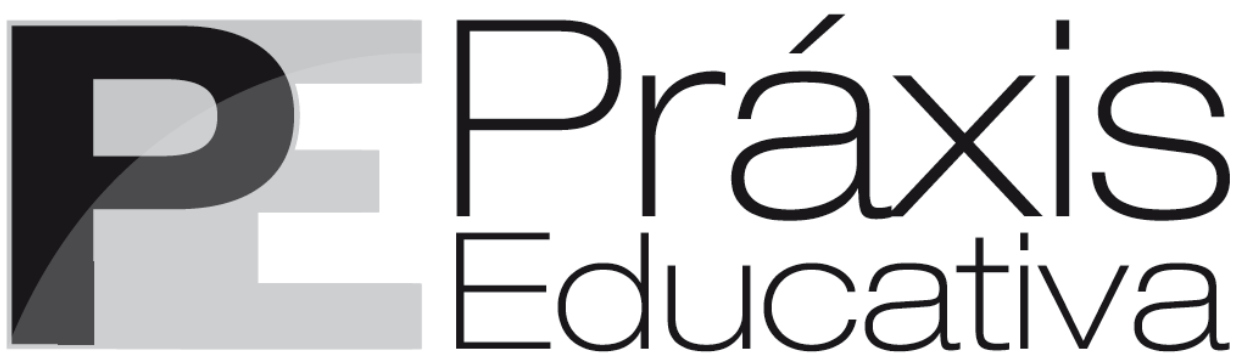

ISSN 1809-4309 (Versão online) DOI: 10.5212/PraxEduc.v.11i3.0005

\title{
As posições-sujeito (Estado e gestores) diante das avaliações em larga escala no Ensino Superior brasileiro
}

\section{Subject-positions (State and managers) regarding large-scale evaluation in the Brazilian higher education system}

\section{Posiciones-sujeto (Estado y gerentes) antes de las evaluaciones a gran escala en la educación superior de Brasil}

\author{
Taise Feldmann* \\ Osmar de Souza* \\ Marcia Regina Selpa Heinzle
}

Resumo: Diante das avaliações em larga escala no Ensino Superior Brasileiro, este artigo objetiva a) analisar as posições-sujeito do Estado e dos coordenadores de cursos de graduação e b) compreender as influências das políticas de avaliação nos currículos da Educação Superior. Trata-se de uma pesquisa de cunho qualitativo, cujo corpus constitui-se de discursos de cinco coordenadores de cursos da área da saúde analisados por meio do método indutivo. As reflexões teóricas baseiam-se em pesquisas sobre a avaliação no ensino superior no que tange às condições de produção das avaliações no cenário mundial e nacional e também em teóricos da Análise do Discurso Francesa. Os resultados apontam que tais posições são interpeladas tanto pelos efeitos ideológicos do Estado, quanto pela posição-sujeito de coordenador/gestor de curso e produzem efeitos de sentido de acatamento, regulação e/ou controle e resistência e/ou descontentamento.

Palavras-chave: Posições-sujeito. Avaliação em larga escala. Currículo.

Abstract: Taking into consideration large-scale evaluations in the Brazilian higher education system, this paper aims at (a) analyzing the subject-positions, namely, the State and graduation course coordinators; and (b) understanding the impact of evaluation policies in higher education curricula. This is a qualitative study, whose corpus comprises the discourse of five course coordinators in the health area, analyzed through the inductive method. The theoretical background is based on research on evaluation in higher education regarding the conditions of production of evaluations in the global and national scenarios and also on the French Discourse Analysis theory. Results revealed that there are political and economic interventions in large-scale national evaluations applied nowadays and that these interventions directly reflect on the curricula dynamics, as well as on the identity and self-image of Higher Education Institutions.

Keywords: Subject-positions. Large-scale evaluations. Curriculum.

\footnotetext{
* Mestre em Educação pela Universidade Regional de Blumenau (FURB). E-mail: <taise.feldmann@gmail.com>.

** Professor da Universidade Regional de Blumenau (FURB). E-mail: <souza.osmars@gmail.com>.

*** Professor da Universidade Regional de Blumenau (FURB). E-mail:<selpamarcia@gmail.com>.
} 
Resumen: A la vista de la amplitud de las evaluaciones en la enseñanza superior de Brasil, el artículo objetiva a) analizar las posiciones-sujeto del Estado y de los coordinadores de cursos de grado y b) comprender las influencias de las políticas de evaluación en los currículos de la Educación Superior. Se trata de una pesquisa de naturaleza cualitativa, cuyo corpus está constituido por discursos de cinco coordinadores de cursos del área de la salud, analizados por el método inductivo. Las reflexiones teóricas están sedimentadas en pesquisas sobre la evaluación en la enseñanza superior sobre las condiciones de producción de las evaluaciones en el escenario mundial y nacional y aún en teóricos del Análisis del Discurso de línea Francesa. Los resultados apuntan que hay intervenciones políticas y económicas en las evaluaciones nacionales, en gran parte, aplicadas en los días actuales y que esas intervenciones reflejan directamente en la dinámica de los currículos, bien como en la identidad y autoimágenes de las Instituciones de Enseñanza Superior.

Palabras clave: Posiciones-sujeto. Evaluación en amplitud. Currículo.

\section{Introdução}

O conceito de posição-sujeito é discutido neste artigo por meio dos estudos da Análise do Discurso - AD Francesa e, assim sendo, o compreendemos como a posição ocupada pelo sujeito para expor os seus discursos. Essa posição é determinada pelas condições de produção em que o sujeito está inserido e, desse modo, a posição-sujeito é determinada pela forma sujeito-histórica que, na sociedade atual, apresenta a contradição de que o sujeito é "ao mesmo tempo livre e submisso. Ele é capaz de uma liberdade sem limites e uma submissão sem falhas: pode tudo dizer, contanto que se submeta à língua para sabê-la" (ORLANDI, 2001, p. 50).

A partir desses pressupostos, este artigo foi embasado em uma pesquisa mais ampla, desenvolvida num Programa de Pós-graduação/Mestrado em Educação de uma Universidade do sul do Brasil, que teve como tema os efeitos de sentido sobre o Exame Nacional de Desempenho de Estudantes - Enade, nos discursos de coordenadores de cursos de graduação na área da saúde.

Objetiva-se, portanto, discutir as diferentes posições-sujeito assumidas pelo Estado e pelos coordenadores de cursos diante do complexo contexto avaliativo que sofre, atual e constantemente, intervenções e, consequentemente, mudanças. Dentre as causas dessas intervenções, estão as influências das políticas oficiais de avaliação nos currículos da Educação Superior. Assim, consideramos que tais políticas são reinterpretadas em vários contextos pelos sujeitos sociais (BALL; MAINARDES, 2011). Diante disso, o movimento dos gestores aponta para uma questão constituinte: a interpelação; na qual as políticas públicas ligadas às avaliações em larga escala interpelam as posições-sujeito e produzem efeitos ideológicos e de sentido, nem sempre percebidos pelos sujeitos.

Quanto à metodologia, esta pesquisa caracteriza-se por ser de cunho qualitativo, pois busca compreender fenômenos, ou seja, as posições-sujeito diante das avaliações, segundo as perspectivas dos sujeitos envolvidos, como comportamentos e experiências humanas em seus contextos (BOGDAN; BIKLEN, 1994). A geração de dados aconteceu por meio de entrevistas semiestruturadas. O critério de escolha dos gestores/coordenadores foi o contato constante destes com os resultados das avaliações externas e a experiência com tensões e responsabilidades para alcançarem resultados positivos. Os dados foram analisados de forma indutiva, interpretados com base na AD Francesa, Michel Pêcheux e Eni Orlandi, paralelamente aos documentos referentes às políticas públicas de avaliação da educação superior no Brasil (Lei no 9.394, de 20 de dezembro de 1996, Lei no 10.861, de 14 de abril de 2004, Portaria Inep no 255, de 02 de junho de 2014).

Práxis Educativa, Ponta Grossa, p. 605-620, v. 11, n. 3, set./dez. 2016 Disponível em: <http://www.revistas2.uepg.br/index.php/praxiseducativa> 
Dessa forma, faz-se, inicialmente, uma breve contextualização da avaliação da educação superior no cenário mundial, na tentativa de mostrar suas concepções ao longo dos anos. Em seguida, discutem-se os dados a partir da análise das posições-sujeito do Estado e dos gestores/coordenadores de cursos diante das avaliações em larga escala e as influências das políticas de avaliação nos currículos da Educação Superior. Por último, algumas considerações acerca da análise dos discursos.

\section{As posições-sujeito do Estado: a avaliação da Educação Superior e a influência do reformismo}

As avaliações de desempenho dos estudantes e de controle externo das instituições de Ensino Superior acontecem desde as primeiras Universidades da Idade Média. Dessa forma, as avaliações estão cada vez mais naturalizadas (DIAS SOBRINHO, 2010), incorporadas ao cotidiano educativo e, na educação superior, dá-se ainda maior destaque, devido às influências das reformas do Estado, na economia, na cultura e na sociedade. Percebemos isso por meio do crescente interesse do Estado pelas avaliações. As políticas de avaliação, no sistema mundial, vêm percorrendo um caminho de crescente controle nos processos avaliativos, conduzindo a uma extrema intervenção do Estado na educação. Esse movimento é chamado de globalização da educação (AFONSO, 2000), a partir do qual, os países buscam se adequar às expectativas do mercado mundial.

Nos últimos 50 anos, devido às crises e restrições econômicas e programas de bem-estar em larga escala, principalmente nos países centrais, a avaliação foi incluída nas agendas políticas dos governos e passou a ser interesse não só do âmbito educativo, como também das esferas econômicas e industriais (DIAS SOBRINHO, 2003). Esse interesse se deve a três razões essenciais: mão de obra qualificada, austeridade orçamental e à responsabilidade pela gestão escolar, partilhada entre autoridades centrais e locais (AFONSO, 2000).

Nesse sentido, compreendemos que a avaliação ultrapassa o âmbito do processo das aprendizagens, pois está inserida em vários domínios do Estado, como nas produções sociais, políticas públicas e políticas educacionais (DIAS SOBRINHO, 2003). A inserção da avaliação nessas diferentes esferas de produção potencializa a influência das políticas de avaliação nos currículos da Educação Superior e a utilização da avaliação como um instrumento de controle e poder do Estado sobre as instituições.

As avaliações externas, de modo geral, iniciaram com maior intensidade em países centrais, como os Estados Unidos, Grã-Bretanha e demais países industrializados. Segundo Dias Sobrinho (2003), foi a partir de 1960 que a avaliação entrou nas discussões das agendas e estratégias governamentais.

Nos EUA, testes como o Scholastic Aptitude Test $(S A T)^{1}$ mostraram que muitos alunos não tinham o domínio de assuntos considerados fundamentais e necessários à indústria. Como consequência, novas metodologias de avaliações foram criadas para que o Estado pudesse ter um maior controle sobre a educação. Os resultados marcaram o ano de 1983 como o começo do mais recente ciclo de reformas dos Estados Unidos, no qual foram inseridas normas mais rígidas e também testes para minimizar uma nação que era considerada de risco por não dominarem assuntos considerados fundamentais e necessários à indústria, assim, não trariam bom resultados (lucros) para as empresas (AFONSO, 2000).

\footnotetext{
${ }^{1}$ SAT (Teste de Aptidão Escolar): utilizado pelas universidades americanas em seus processos de admissão para graduação.
}

Práxis Educativa, Ponta Grossa, p. 605-620, v. 11, n. 3, set./dez. 2016 Disponível em: <http://www.revistas2.uepg.br/index.php/praxiseducativa> 
As posições-sujeito (Estado e gestores) diante das avaliações em larga escala no Ensino Superior brasileiro

Com a queda da competitividade dos Estados Unidos devido aos baixos índices educacionais demonstrados pelo $S A T$, os grupos econômicos ficaram incomodados e o Estado interveio, conciliando seus poderes de governo aos dos líderes empresariais, a fim de resolver esse problema na educação. Ainda, com uma retórica política, o Estado mobilizou os meios de comunicação e opiniões públicas para passar a ideia de que era a administração central do país a verdadeira interessada em alterar a agenda para a educação (AFONSO, 2000).

Entretanto, a educação americana só tomou um novo rumo com a eleição de Bill Clinton no ano de 1992, cujo plano de governo criou expectativas de um novo projeto educacional que considerasse a equidade e a diversidade. Nesse período surge a avaliação de desempenho baseada na teoria construtivista e os portfólios. Esses instrumentos tinham por objetivo além de romper com as formas tradicionais de avaliação, favorecer mediações entre o ensinar e o aprender . Porém, os registros indicam que essas reformas não alcançaram o seu propósito inicial (AFONSO, 2000).

Segundo Dias Sobrinho (2003), na França, a avaliação sofreu influências da economia no que diz respeito às políticas de financiamentos e isso interferiu diretamente na autonomia das instituições de ensino. $\mathrm{O}$ autor destaca que essa caraterística torna evidente o deslocamento das estruturas de controle dos processos para os resultados.

Na Grã-Bretanha, a partir do governo de M. Thatcher, em 1979, as universidades foram direcionadas a um perfil próximo ao empresarial (DIAS SOBRINHO, 2003). Desse modo, desde os anos de 1980, a avaliação na Inglaterra vem sendo utilizada como um instrumento para "um processo de privatização da educação superior", para que sejam "cada vez mais parecidas com as empresas de negócios, como declarado no Relatório Jarrat, de 1985" (DIAS SOBRINHO, 2003, p. 61-62). Esse processo de privatização surgiu da concepção de que se as instituições de ensino se adequassem às regras de mercado, e isso inclui a competitividade, produziriam com mais eficiência e seriam mais úteis à indústria. Com o Estado legitimando essa atitude, as Universidades públicas e privadas passaram a disputar as verbas, convênios e outros serviços do governo, e a avaliação se tornou o instrumento para distribuir esses recursos. Desse modo, a avaliação passou a ser utilizada para medir a produtividade no ensino e os dados quantitativos foram utilizados como indicadores nas pesquisas (DIAS SOBRINHO, 2003).

No México, a competição por recursos também acontece, mas numa avaliação vinculada à pesquisa. $\mathrm{Na}$ educação superior, o país vem sofrendo os impactos do North American Free Trade Agreement - $\mathrm{Nafta}^{2}$ e "deve se ajustar aos padrões de qualidade, às normas de credenciamento e reconhecimento de cursos, aos currículos e políticas de formação definidos pelos países consorciados" (DIAS SOBRINHO, 2003, p. 65) - Canadá, Estados Unidos da América e México. Segundo o autor, nesse caso, "se pratica a avaliação predominantemente como política de Estado".

Próxima ao cenário brasileiro, a Argentina também vem utilizando a avaliação como um instrumento de legitimação do poder do Estado sobre as políticas públicas da educação superior. Essa legitimação se dá através da Lei $n^{\circ} 24.521 / 95$, que fixou os critérios por meio dos quais as instituições devem se governar; estabeleceu as formas de financiamento associadas à avaliação; formulou as diretrizes de gestão financeira; flexibilizou a abertura de novos cursos, especialmente os de regime privado, e criou os organismos reguladores. Os mais importantes desses organismos

\footnotetext{
2 Tratado Norte-Americano de Livre Comércio: é um termo que envolve os países da América do Norte (Estados Unidos, México e Canadá) e o Chile como associado, que visa à aproximação econômica desses países em busca de melhora mútua entre os mesmos. Esse acordo trabalha com taxas menores como política de comércio entre esses países.
} 
são o Conselho de Educação Superior, a Comissão Nacional de Credenciamento e Avaliação (Coneau) e o Fundo de Melhoramento da Qualidade Educativa (Fomec) (DIAS SOBRINHO, 2003, p. 66).

No Chile, a "função classificatória da avaliação é, pois, bastante evidente e de enorme importância para as políticas oficiais" (DIAS SOBRINHO, 2003, p. 65). O autor explica que com a implantação do sistema de modernização, em 1973, o Chile instituiu políticas de regulação e privatização da educação e tornou as Universidades dependentes do bom desempenho dos alunos numa avaliação nacional, visto que esses bons alunos, consequentemente, trariam bons resultados para as Universidades e, assim, estas conseguiriam os recursos do governo.

No Brasil, as avaliações da educação superior, até o final dos anos de 1960 e os primeiros anos de 1970, não tinham modelos sólidos, nem investimentos em pesquisas educacionais como nos países centrais. Segundo Dias Sobrinho (2003), o que havia estava frágil e foi assujeitado pelo golpe militar que durou cerca de vinte anos (1964-1985), tornando o Brasil ainda mais dependente dos países centrais. Neste período, as Universidades não tinham recursos, tampouco profissionais qualificados para pesquisas ou autonomia administrativa.

Com a reforma universitária de 1968, ainda na ideologia de capital humano, ampliaram-se as universidades públicas e a infraestrutura de pesquisas, mas numa perspectiva de mercado, com foco no desenvolvimento econômico. Nesse processo de ampliação e modernização, o regime militar, aos poucos, criou "o regime de dedicação integral à docência e à pesquisa e cria um sistema de pós-graduação, que se consolidou de forma progressiva e, até hoje, apresenta-se como o mais amplo e importante da América Latina" (DIAS SOBRINHO, 2003, p. 69). Com a crise econômica e o esgotamento militar nos anos 1980, a avaliação da educação superior se tornou "o instrumento básico para orientar a distribuição dos recursos públicos e a imposição da racionalidade da eficiência" (DIAS SOBRINHO, 2003, p. 72). Esse período, de 1983 até 1992, foi considerado a primeira fase da avaliação da educação superior no Brasil, chamada de "construção da agenda" (ALMEIDA JÚNIOR, 2002, p. 179). Nessa fase, ocorreram muitas discussões entre associações, IES, MEC, entre outros órgãos, e também a implantação de programas para as primeiras experiências com a avaliação, como o PARU - Programa de Avaliação da Reforma Universitária e GERES - Grupo de Estudos da reforma da educação superior, avaliações completas e sistemáticas das IES, entre outras (ALMEIDA JÚNIOR, 2002).

A primeira experiência com a avaliação, conforme Almeida Júnior, foi o PARU, que tinha o propósito de averiguar a gestão e o ensino das IES. Sem ter o apoio político necessário, o programa foi desativado no ano de 1984. Nessa fase, os governantes da época reforçavam a avaliação como um instrumento para controlar a educação, e, exemplo disso, são as políticas de privatização no sentido de garantir, por meio das avaliações, "excelência, eficiência, produtividade e uma gestão eficaz" (DIAS SOBRINHO, 2003, p. 73). Segundo Afonso (2000), esse discurso acarreta questões morais, como a culpa, quando há fracasso dos alunos e das IES, e uma maior cobrança de produtividade.

O GERES, criado em 1986, foi um grupo que reforçou as ideias dos governantes expostas anteriormente, como a proposta de criar um exame nacional na educação superior brasileira, que mais tarde se concretizou com o Exame Nacional de Cursos, o conhecido "Provão" e a Avaliação das Condições de Ensino (ACE), e ainda, o Programa de Avaliação Institucional das Universidades Brasileiras - PAIUB.

A segunda fase da avaliação da educação superior no Brasil foi chamada de "formulação da política", no período de 1993 até 1995, e teve como principais caraterísticas o "espaço político de trocas, conflitos e poder" (ALMEIDA JÚNIOR, 2002, p. 180). Podemos dizer, então, que na 
década de 1980 a avaliação já fazia parte das agendas políticas e econômicas brasileiras, porém, somente na década de 1990 é que a avaliação se tornou o real foco das discussões, levando assim o nome de "a década das avaliações". Nesse período, principalmente no ano de 1995, a avaliação passou a averiguar as IES quanto ao cumprimento das exigências do mercado e das indústrias com "controle rigoroso sobre os perfis profissionais, as competências e habilidades demandadas pelo mercado" (DIAS SOBRINHO, 2003, p. 75).

A partir do ano de 1995, uma terceira fase se inicia, denominada a fase de "consolidação ou implementação da proposta governamental" e permanece até o ano de 2003. Nesta fase, novos mecanismos de avaliação são implementados pelo MEC, como o Exame Nacional de Cursos ENC, no ano de 1996. Segundo Almeida Júnior (2002), nesse período houve um aumento do controle das atividades do ensino superior devido às alterações nas Leis $n^{\circ} 9.131 / 95$ e $n^{\circ}$ 9.192/95 e à edição da nova LDB, LEI no 9.394/96, que regulamenta as diretrizes e bases da educação no Brasil.

Com base nas discussões sobre as três fases de avaliação, vimos que o interesse principal do Estado era criar uma avaliação que "verificasse em termos práticos e imediatos a qualidade das instituições, entendida como capacidade em atender as demandas de mercado, independentemente se essas instituições são de natureza particular ou pública" (ALMEIDA JÚNIOR, 2002, p. 181). Segundo o autor citado, o Estado, devido a interesses políticos e econômicos deixou de lado o PAIUB, que exercia uma avaliação mais formativa, e passou a adotar o uso do ENC, um instrumento de controle legal que atendia às expectativas do mercado.

No ano de 2004, como numa quarta fase da avaliação da educação superior no Brasil, a partir de novos olhares e discussões, foi criado o Sistema Nacional de Avaliação da Educação Superior - SINAES, com o princípio de valorizar a diversidade e a alteridade no processo avaliativo, conforme será discutido na próxima seção.

Em suma, compreendemos que a avaliação evoluiu muito desde o final do século XIX (DIAS SOBRINHO, 2003), entretanto, ao mesmo tempo, vimos que muitos dos propósitos e compreensões dessas décadas estão ainda presentes na posição-sujeito que o Estado ocupa nos dias de hoje, como a utilização da avaliação como um instrumento de medição e verificação da aprendizagem. Com essa utilização da avaliação como uma prestação de contas (accountability), criou-se a ideia de que "qualidade corresponde à eficiência, que se obtém mediante a racionalidade empresarial” (DIAS SOBRINHO, 2003, p. 59).

Desse modo, com reformas constantes ao longo da história e suas respectivas concepções e ideologias, a avaliação teria apenas a função de controle, fiscalização e intervenção na educação, e estaria a serviço das autoridades governamentais e do mercado mundial para induzir a educação superior a uma formação profissional, com uma "pedagogia e um currículo ajustados às demandas da economia e às necessidades de dominação ideológica dos governos" (DIAS SOBRINHO, 2003, p. 67). Diante desse contexto avaliativo, o Estado assume uma posiçãosujeito contingenciada por fatores externos, como o mercado mundial e os interesses políticos que, conforme apresentado, influenciam diretamente a avaliação.

Para compreender essas influências, a seguir, discutimos sobre a quarta fase da avaliação a partir do Sistema Nacional de Avaliação da Educação Superior - SINAES, e, consequentemente, do Exame Nacional de Desempenho de Estudantes - Enade.

Práxis Educativa, Ponta Grossa, p. 605-620, v. 11, n. 3, set./dez. 2016 Disponível em: <http://www.revistas2.uepg.br/index.php/praxiseducativa> 


\section{SINAES e ENADE: propósitos e desmontes}

Conforme exposto anteriormente, o SINAES foi instituído no ano de 2004, por meio da Lei $\mathrm{n}^{\circ}$ 10.861, para avaliar as instituições de Ensino Superior (Avalies), os cursos de graduação (ACG) e os estudantes (Enade). Os resultados obtidos nessas avaliações têm como objetivo traçar um panorama da qualidade dos cursos e das Instituições de Ensino Superior - IES - do país (WAITZ; ARANTES, 2009), exigir as melhorias necessárias na educação superior e embasar as políticas públicas.

No que se refere ao Enade, o objetivo é avaliar os seguintes itens: o desempenho dos estudantes em relação aos conteúdos programáticos previstos nas Diretrizes Curriculares Nacionais - DCN dos cursos de graduação; o desenvolvimento de competências e habilidades necessárias ao aprofundamento da formação geral e profissional; o nível de atualização dos estudantes com relação à realidade brasileira e mundial (BRASIL, 2013). Cada área do conhecimento é avaliada trienalmente, sendo que a primeira aplicação do Enade, em 2004, avaliou as áreas da saúde e agrárias (BRASIL, 2013).

O referido exame "é composto pela prova, o Questionário de Avaliação Discente da Educação Superior (ADES), o questionário dos coordenadores de curso e a percepção dos alunos sobre a prova" (BRITO, 2008, p. 842). A prova do Enade apresenta 10 questões de formação geral e 30 de conteúdos específicos de cada área do conhecimento, que buscam avaliar as habilidades e competências e ainda questões interdisciplinares (BRITO, 2008).

Segundo Brito (2008), esse novo olhar proposto pelo SINAES por meio da Comissão Especial de Avaliação do MEC, foi um avanço na educação superior, visto que articula a avaliação de curso e a avaliação institucional, avaliando assim a qualidade do curso nas suas condições de produção, ou seja, na realidade da instituição. Já os exames anteriores, como o Provão, possuíam um caráter de vigilância e de normalização. Assim, segundo Bordignon e Cimadon (2012, p. 58) "foi tudo cuidadosamente presumido e planejado, para que todos pudessem participar e contribuir para a consecução dos objetivos que alavancam o processo avaliativo". Dentre os princípios desse sistema estão a responsabilidade social e o reconhecimento das diversidades e particularidades num processo contínuo e coletivo. No entanto, a prática reforça o controle e fiscalização do Estado que, por meio dos resultados dos três momentos avaliativos do SINAES, regula e supervisiona a educação com "o credenciamento e a renovação de credenciamento de instituições de educação superior, a autorização, o reconhecimento e a renovação de reconhecimento de cursos de graduação" (BRITO, 2008, p. 842).

Segundo Brito (2008), outra influência dos componentes do SINAES ocorre nos Projetos Pedagógicos dos Cursos de graduação, visto que o sistema avalia se os projetos se enquadram nas exigências das Diretrizes Curriculares Nacionais - DCN, e ainda, com o Enade, que avalia as competências e habilidades dos acadêmicos. Assim, o SINAES busca que os órgãos responsáveis nas IES construam PPCs que ampliem as "habilidades acadêmicas que serão desenvolvidas e [...] as competências profissionais que o estudante deverá demonstrar possuir ao final do curso" (BRITO, 2008, p. 844).

Dessa forma, o SINAES direciona mudanças também curriculares e os currículos atendem às necessidades macros e micros, ou seja, as demandas nacionais e as demandas locais, que são as especificidades de cada região onde as IES se situam. Assim, com o Enade avaliando as habilidades e competências e sendo uma única prova em todo o Brasil, os princípios do SINAES se contradizem, visto que, deseja-se "um modelo único de instituições superiores, em uma evidente irrealidade, em face de um país continental, de condições culturais, econômicas e 
sociais diversificadas" (BORDIGNON; CIMADON, 2012, p. 43). Além desses impasses, Bordignon e Cimadon (2012) apontam outros problemas apresentados pelo SINAES: instrumentos de avaliação únicos para os diferentes tipos de instituições, demasiada importância ao Enade e a falta de instrução in loco aos avaliadores.

A partir do exposto, vimos que a articulação entre a avaliação institucional, a avaliação de cursos e a avaliação dos estudantes não acontece conforme os princípios do sistema. Segundo Bordignon e Cimadon (2012), a maior crítica a esse sistema se refere à dificuldade de realizar avaliações objetivas que consigam mostrar efetivamente o nível de ensino das IES no país. Como consequência dessa dificuldade temos a centralização do Enade no processo avaliativo, dando, consequentemente, maior visibilidade ao Conceito Preliminar de Curso - CPC e ao Índice Geral de Cursos - IGC. Percebe-se que ao longo do processo houve mudanças na sua operacionalização, por exemplo, a prova do Enade, até o ano de 2010, foi aplicada aos ingressantes e concluintes dos cursos de graduação, no entanto, a partir de 2011, somente os concluintes dos cursos participam da prova.

O INEP também institui anualmente, por meio de portarias, as especificidades de cada edição do Enade, sendo que o componente de Formação Geral é seguido em todas as edições. Além dos elementos do perfil profissional, conforme consta nos objetivos do exame, a portaria apresenta as habilidadese competências exigidas, como a leitura e interpretação de textos, análise crítica de informações, administração de conflitos e soluções, entre outros.

Conforme observamos, as considerações do componente de formação geral condizem com as exigências de uma formação profissional mais ampla e, desse modo, são aceitáveis quando a prova do Enade é aplicada somente aos concluintes dos cursos de graduação. Entretanto, há sinalizações de questões que direcionam a avaliação na perspectiva de mercado (funcionalidade eficácia - eficiência) (BORDIGNON; CIMADON, 2012). Outros desvios ocorrem em relação ao tratamento dado aos resultados do Enade, que são transformados em rankings ${ }^{3}$, tanto pela mídia quanto pelos gestores e Estado.

Dessa forma, os resultados do Enade passaram a ser valorizados demasiadamente, assim, os dados estatísticos, que têm o objetivo de mostrar a realidade das IES, nem sempre podem ser considerados dados reais, visto que não há uma devida preocupação e dedicação com as avaliações nacionais, tanto na elaboração, quanto no envolvimento dos sujeitos integrantes deste processo.

Segundo Calderón, Poltronieri e Borges (2011, p. 821):

\begin{abstract}
Dos três instrumentos de avaliação, o Enade adquiriu grande destaque no Ministério da Educação e na mídia, emergindo novamente os rankings, apontados por Dias Sobrinho (2010) e Brito (2008), como uma atitude equivocada da mídia. Assim, diferentemente do que propunham os seus formuladores, o Enade acabou sendo tomado como principal fonte de informação para a formulação dos índices de qualidade.
\end{abstract}

Ressaltamos que cabe também às IES utilizar de forma adequada os dados dos resultados obtidos no Enade, uma vez que "a responsabilidade social de uma instituição, é responder, com qualidade, às exigências e às necessidades da sociedade" (BORDIGNON; CIMADON, 2012, p. 45) e não o que muitas IES vêm fazendo, que é "promover ampla propaganda dos itens positivamente avaliados, ainda que parciais e destacados do contexto, para melhorarem sua

\footnotetext{
${ }^{3}$ Enfatizamos que algumas IES utilizam os resultados dos cursos bem avaliados como marketing, porém, omitem os que foram mal avaliados.
}

Práxis Educativa, Ponta Grossa, p. 605-620, v. 11, n. 3, set./dez. 2016 Disponível em: <http://www.revistas2.uepg.br/index.php/praxiseducativa> 
imagem pública, e, com isso, obterem vantagens competitivas no mercado educacional" (DIAS SOBRINHO, 2010, p. 215).

Sobre os resultados em índices numéricos, Dias Sobrinho (2002, p. 63) argumenta que "não bastam os resultados estatísticos para dar conta da complexidade de um fenômeno humano, de uma instituição social ou de um sistema educativo". O autor também cita que "mediante procedimentos de quantificação e comparação, introduzem no sistema um forte componente de competitividade nos níveis internos das instituições educativas e nas suas relações com as demais" (DIAS SOBRINHO, 2004, p. 718). Diante deste contexto, descaracterizaram-se os princípios do SINAES, como a equidade e o processo contínuo da avalição, que consideram os fatores sociais e as suas diversidades, em detrimento da perspectiva da avaliação somativa.

A partir do exposto, compreendemos que o Estado continua assumindo uma posiçãosujeito ligada aos interesses políticos e econômicos, haja vista que intervém diretamente nas IES por meio das avaliações. Já os coordenadores, como veremos adiante, assumem uma posiçãosujeito de acatamento ao o que o Estado impõe por meio das políticas públicas, uma vez que apenas reproduzem as normas e o controle avaliativo.

Embora as críticas estejam presentes no cenário atual, reconhecemos que o Enade ainda é um avanço, comparado ao antigo Provão, pois compreende em seus princípios uma concepção de avaliação dinâmica e formativa, na qual o interesse principal é avaliar continuamente para qualificar o processo educativo.

Para ampliar as comprensões acerca da avaliação e compreender as influências nos currículos da Educação Superior, abordamos, a seguir, algumas perspectivas avaliativas.

\section{As perspectivas das avaliações emergentes}

De acordo com as discussões anteriores, considera-se que estamos vivendo uma quarta fase da avaliação que, segundo Machado (2013), compreende a avaliação como um processo sociopolítico, emergente, colaborativo, de ensino-aprendizagem, contínuo, recursivo e altamente divergente, com resultados imprevisíveis e que cria a realidade. Para compreender melhor esses processos, ampliamos as discussões a seguir.

A avaliação como um processo sociopolítico é considerada ao relacionarmos a avaliação a fatores sociais, políticos e culturais, sem os quais "a avaliação corre o risco de se tornar uma atividade inútil e sem significado" (MACHADO, 2013). Nessa perspectiva, a avaliação leva em conta não somente efeitos de sentido acadêmicos, mas também as condições de produção dos sujeitos envolvidos no processo avaliativo.

O autor compreende a avaliação como um processo emergente, ao considerar que só pode ser objetiva e realista se respeitar as condições de produção de cada IES. Outro processo abordado por Machado (2013) é a avaliação colaborativa, na qual há uma participação concreta de todos os sujeitos envolvidos com o objetivo de colaborar para que haja ações de melhorias a partir das avaliações. Nesse sentido, a avaliação preocupa-se com a continuidade e espera que a partir de seus resultados sejam feitas melhorias. O autor discute ainda a avaliação como um processo de ensino-aprendizagem, no qual os sujeitos envolvidos aprendem simultaneamente, visto que, a partir de seus conhecimentos, avaliador e avaliado buscam melhorias por meio das avaliações. Nesse processo, a avaliação é tida como meio para a busca de um ensino de qualidade e propõe troca de conhecimentos. 
As posições-sujeito (Estado e gestores) diante das avaliações em larga escala no Ensino Superior brasileiro

Outra perspectiva, complementar às demais, é a avaliação como um processo contínuo, recursivo e altamente divergente. Essas características significam que a avaliação é inacabada e infinita, uma vez que que, em cada avaliação há novas compreensões e possibilidades. Nesse sentido, a avaliação é também um processo de resultados imprevisíveis, visto que, apresenta diferentes resultados em suas várias aplicações e se reconstrói a partir dos problemas identificados. Os resultados da avaliação podem até ser contraditórios e é isso o que torna a avaliação um agente de mudanças.

No que diz respeito ao Enade, seus princípios correspondem às características da quarta fase de avaliação, na expectativa de que as IES utilizem de forma adequada os resultados obtidos, buscando cada vez mais qualidade em seus cursos e, consequentemente, na formação. $\mathrm{O}$ que questionamos é se as IES utilizam os resultados para esse fim ou apenas para marketing e, ainda, se o Estado intervém da forma adequada por meio do Enade, visto que, muitas IES sofrem com boicotes e/ou a falta de compreensão e reconhecimento da avaliação por parte dos alunos e também dos professores que podem influenciar na motivação para realizar oexame.

Por fim, Machado (2013) considera a avaliação um processo que cria a realidade, pois, conforme exposto anteriormente, é uma "(re)construção da 'realidade" a partir dos diferentes resultados e problemas identificados. Nesse sentido, é por meio da avaliação que se busca conhecer a realidade das IES e exigir que busquem melhorias constantes.

Pertinente aos processos expostos por Machado (2013), o autor Dias Sobrinho (informação verbal) ${ }^{4}$ considera a avaliação um fenômeno social e, portanto, ética e política, carregada de valores tanto ideológicos quanto axiológicos. Segundo o autor, as transformações sociais produzem mudanças na educação, e as avaliações são a máquina, a força para essas mudanças.

A partir das perspectivas discutidas, chegamos a duas funções que são atribuídas à avaliação por Dias Sobrinho (2003): a função proativa, que é formativa e visa "melhorar e desenvolver o objeto em foco, seja um indivíduo, grupo," etc., e a função retroativa, que é somativa e é praticada como uma prestação de contas (accountability), como as provas que utilizam instrumentos de medição, classificação e seleção. Dessa forma, compreendemos que a avaliação é essencial, e, portanto, necessária para que se alcance a qualidade educacional tão almejada, entretanto, conforme Dias Sobrinho (2002, p. 47) "importante é que a avaliação não se reduza a controlar, tampouco seja a supressão da autonomia e da liberdade intelectual, mas sim um instrumento [...] a projetar novas possibilidades de construção".

A seguir, dedicamo-nos a olhar para a posição-sujeito dos coordenadores de cursos, que é o lugar histórico social de onde o sujeito fala. As análises serão discutidas a partir dos discursos de acatamento, de regulação e/ou controle, e de resistência e/ ou descontentamento.

\section{Posição-sujeito de acatamento e o impacto no currículo}

O conceito de acatamento é compreendido neste artigo como a aceitação do sujeito em se relacionar com ações do Estado, como as avaliações nacionais em larga escala que são instituídas por políticas públicas e, consequentemente, pelo Enade. Esse acatamento pode acontecer, em razão da posição-sujeito que os coordenadores de cursos ocupam, em que há uma relação de subordinação à instituição, pois os resultados do Enade, que são utilizados como base para o

\footnotetext{
${ }^{4}$ Conferência de abertura do III Congresso Internacional de Avaliação e VIII Congresso Internacional de Educação proferida por José Dias Sobrinho, na FAURGS em 07 de outubro de 2013.
}

Práxis Educativa, Ponta Grossa, p. 605-620, v. 11, n. 3, set./dez. 2016 Disponível em: <http://www.revistas2.uepg.br/index.php/praxiseducativa> 
CPC e o IGC, incidem sobre o curso trazendo uma responsabilização mais intensa sobre os gestores.

Conforme discutido anteriormente, a avaliação parece se deslocar da sua função de garantir a qualidade educacional para responder às ideologias do Estado, projetar resultados estatísticos e atender às exigências do mercado. Isso vem acontecendo nos últimos 50 anos, nos quais a avaliação foi incluída nas agendas políticas dos governos e passou a ter interesse não só no âmbito educativo, mas também nas esferas econômicas e industriais (DIAS SOBRINHO, 2003).

Dessa forma, os efeitos de sentido da avaliação com fim mercadológico e de controle interpelam os sujeitos desde que esse deslocamento iniciou e, em nossa compreensão, justificam o acatamento que muitos têm hoje em relação às políticas públicas impostas pelo Estado. Segundo Orlandi (2001), o sujeito é social e não é a origem do seu dizer, visto que é interpelado por outros sujeitos. E nessa interpelação é que ocorrem as produções dos efeitos de sentido, que são passadas adiante, por meio do discurso.

Os discursos dos sujeitos entrevistados apontam para a relação de poder do Estado sobre as IES e, consequentemente, sobre os coordenadores de cursos, uma vez que, por meio do Enade, o Estado pode controlar o ensino com a homogeneização e a definição de padrões. Essas ações acabam classificando as IES por meio de notas: "quando o nosso curso foi pontuado com nota dois... a gente sabia que não correspondia com a realidade" (D1), porém, essas notas nem sempre são equitativas e, mesmo assim, impactam diretamente nos cursos, que buscam adequar os seus currículos e processos avaliativos ao modelo Enade: "mas mesmo assim nós nos mobilizamos" (D1); "a gente reestruturou pensando muito nas questões Enade... o Enade não ficou alheio... ab! essa reconstrução do PCC... então ele teve uma influência direta também na reestruturação do currículo do nosso curso e continua tendo" (D2).

Percebe-se que há também impactos positivos, pois um dos propósitos avaliativos é rever o processo educativo, e, se necessário, propor mudanças. Portanto, as reformulações curriculares a partir do Enade, compreendido como busca contínua de melhorias, parece-nos ser um indicador relevante: "tomamos várias medidas pra tentar melhorar e sempre melhorar, melhorar, melhorar" (D1), "nós comę̧amos a repensar o currículo e as nossas avaliaçoes dentro do curso" (D2).

Percebemos que o coordenador de curso exerce a posição-sujeito responsável por mediar a comunicação entre os sujeitos envolvidos no processo avaliativo e mobilizar ações de mudanças. Nesse sentido, o coordenador se torna o agente principal, e, segundo Vasconcelos (2010, p. 104), as ações dos coordenadores de cursos têm "forte influência sobre os resultados do processo de ensino-aprendizagem, considerando, assim, que gestão e qualidade do ensino são conceitos inseparáveis".

Um dos discursos retrata que o curso já passou por várias reformulações para se adequar às mudanças das DCN e essa ação torna evidente o impacto do Enade nos currículos dos cursos, que reestruturam seus PPC em busca do padrão estabelecido pelo Estado por meio da avaliação em larga escala. Segundo Brito (2008, p. 844), o currículo de um curso "deve atender o nível geral do esperado para a formação de profissionais de uma mesma área e também as especificidades do entorno." Por outro lado, os discursos apontam para o assujeitamento ideológico, visto que há uma busca constante por padronizar o ensino em nível nacional, sem levar em consideração as diversidades das IES.

Consideramos que a posição-sujeito dos coordenadores pode interferir em outros discursos, visto que, é compreensível que esses sujeitos tenham uma posição pessoal divergente, 
no entanto, há interpelações intra e interinstitucionais. Ainda, há um cruzamento de efeitos de sentido entre os discursos, que produziram novos sentidos e significados sobre o Enade, como de regulação e/ou controle, os quais são analisados a seguir.

\section{Posição-sujeito de regulação e/ou controle}

A regulação e o controle são compreendidos neste artigo como a interferência do Estado na educação, uma vez que a avaliação é um "processo de intervenção direta sobre as decisões, tanto nos níveis mais restritos e internos, quanto em termos de políticas públicas e de sistema" (DIAS SOBRINHO, 2008, p. 201). Assim, mesmo constituída por valores éticos, "na educação superior, principalmente, os mecanismos chamados de avaliação usualmente assumem funções políticas de classificação que legitimam e estimulam instituições, programas, indivíduos e também consolidam mentalidades e estilos" (DIAS SOBRINHO, 2003, p. 35).

Ainda de acordo com o autor supracitado, o controle é uma das funções da avaliação e apresenta duas de suas características: a primeira que se dá por meio de normas e legislações que regulam e asseguram a legitimação dos que as cumprem; a segunda seria a regulação entendida como dinâmica, que busca, por meio do controle, avançar na melhoria da educação (DIAS SOBRINHO, 2004).

Entre os discursos dos sujeitos da pesquisa, apreendemos efeitos de sentido de regulação e/ou controle, conforme segue: "Enade veio pra ter um controle... sobre o nivel do ensino das instituições através de uma avaliação sobre os estudantes que estão saindo... então ele é um instrumento de controle" (D3).

Identificamos a partir deste discurso, sinalizações que o exame, mesmo tendo como objetivo principal ser um instrumento de avaliação para garantir a qualidade da educação, vem tornando-se, cada vez mais, um instrumento de controle e regulação das IES. Segundo Dias Sobrinho (2004) isso acontece devido ao fato de o Estado utilizar as avaliações para interesses políticos e econômicos, como as reformas desejadas na educação superior. A partir do discurso: "ele é um instrumento de controle", o coordenador reproduz efeitos ideológicos do Estado, de que o Enade tem esse fim: regular e controlar o nível de ensino das IES.

O sentido de regulação que o Enade traz faz com que as IES e, consequentemente, coordenadores de cursos, sintam-se sob uma constante fiscalização do Estado, que institui a maneira como se deve agir. Segundo Dias Sobrinho (2004, p. 706), "a avaliação instrumentaliza as reformas educacionais, produzindo mudanças nos currículos, na gestão, nas estruturas de poder, nas configurações gerais do sistema educativo, nas concepções e prioridades da pesquisa". Assim, torna-se um instrumento de regulação e/ou controle de tudo que está sendo realizado pelas e nas IES.

A preocupação com o produto mais do que com o processo avaliativo, discutida até então, também foi apontada pelos coordenadores, quando analisamos os discursos que remetem a efeitos de sentido de resistência e/ou descontentamento, tanto em relação ao Enade de modo geral quanto a características específicas desse exame. 


\title{
Posição-sujeito de resistência e/ou descontentamento
}

Os conceitos de resistência e descontentamento são compreendidos nesta pesquisa como a oposição e a insatisfação do sujeito ao não se identificar com a ideologia dominante (PÊCHEUX, 1988).

O excerto da entrevista com um dos coordenadores produz efeitos de sentido de resistência a esse deslocamento da avaliação para fins de avaliação externa: "esse processo do Enade eu acho que é um processo que deveria existir já dentro da universidade, desde o início... e não essa preparação toda que a gente vem desenvolvendo [...]” (D4).

Compreendemos que a coordenadora discorda da realização de ações desenvolvidas exclusivamente para o Enade, que, para ela, deveriam acontecer durante o processo de formação acadêmica. Segundo Bonamino e Sousa (2012, p. 383):

\begin{abstract}
[...] evidências nacionais e internacionais mostram que principalmente o uso de resultados das avaliações de terceira geração para informar iniciativas de responsabilização forte pode envolver riscos para o currículo escolar. Um deles é a situação conhecida como ensinar para o teste, que ocorre quando os professores concentram seus esforços preferencialmente nos tópicos que são avaliados e desconsideram aspectos importantes do currículo, inclusive de caráter não cognitivo.
\end{abstract}

As palavras das autoras se referem à educação básica brasileira, no entanto, podemos relacionar também com a educação superior. Os efeitos de sentido de resistência e/ou descontentamento são apontados quando um dos coordenadores diz: "eu acho que é um processo que deveria existir já dentro da universidade desde o inicio... e não essa preparação toda que a gente vem desenvolvendo" e "o aluno que sai duma universidade tem que ter plenas condições de faz̧er as atividades não só porque ele vai fazer uma prova" (D4).

Os efeitos de sentido produzidos nos discursos desvelam sua posição-sujeito diante do exame, posição de quem, mesmo resistindo, realiza as ações que a IES institui orientada pelo Estado e pela Instituição. Percebemos que há uma resistência silenciada, e um assujeitamento, oriundo das relações de poder que há nas avaliações, que segundo Dias Sobrinho (2003, p. 73) “é, assumidamente, uma estratégia de imposição e preservação do poder".

Outros discursos também produzem efeitos de sentido de resistência e/ou descontentamento: "ele é feito de maneira idônea e alcance todo o território nacional... ele avalia de uma forma conjunta... e não a aplicação pra cada região" (D5). O discurso do coordenador aponta para um descontentamento quanto à homogeneização realizada pelo Enade, ou seja, à aplicação de uma única prova, visto que a metodologia atual não alcança as diversidades das IES do Brasil. Segundo Dias Sobrinho (2003, p. 156), nos exames nacionais em larga escala, que compreendem "num mesmo processo regiões diferentes e instituições com diversificados níveis de consolidação, não é de estranhar que haja uma espécie de nivelamento por baixo”.

Para o coordenador, o Enade: "Classifica melhor os que têm aquele padrão de ensino e que estejam adequados àquelas perguntas" (D5) e, esse discurso, produz efeitos de sentido que remetem a uma forma de controle do Estado, que privilegia, por meio do Enade, as IES que seguem suas ideologias na formulação dos currículos dos cursos. Dessa forma, mesmo o SINAES tendo como proposta avaliar a qualidade dos cursos de acordo com a realidade de cada IES (BRITO, 2008), pode não conseguir atingir esse objetivo, já que, com o Enade considera as IES como iguais.

Entendemos que os discursos dos gestores/coordenadores remetem aos diferentes efeitos de sentido produzidos pela avaliação, especificamente, o Enade, e que esses sentidos foram 
As posições-sujeito (Estado e gestores) diante das avaliações em larga escala no Ensino Superior brasileiro

interpelados pelas condições de produção da avaliação em larga escala no cenário mundial e nacional que vem, ao longo dos anos, sofrendo influências políticas e econômicas.

\section{Considerações}

Ao longo deste artigo buscamos compreender as posições-sujeito do Estado e dos gestores/coordenadores de cursos diante de avaliações externas, como o Enade e, a partir disso, analisar as implicações das avaliações nacionais no currículo da Educação Superior. Reconhecemos que o Estado assume uma posição-sujeito de interventor/controlador da educação a partir das avaliações nacionais e que os gestores/coordenadores de cursos assumem diferentes posições-sujeito, de acordo com as condições de produção estabelecidas.

Essas posições são: acatamento diante das ações do Estado e regulação em relação aos professores e acadêmicos dos cursos. Identificamos também que as relações entre avaliação e o currículo estão presentes nos discursos dos coordenadores analisados tanto para reorganizá-lo a fim de qualificar a formação dos futuros profissionais, quanto para adequá-lo ao Enade como um fim em si mesmo.

Portanto, essas influências das políticas de avaliação nos currículos da Educação Superior apresentam tanto aspectos positivos, no que diz respeito às IES buscarem constantes melhorias dos currículos e dos processos avaliativos em seus cursos, como também negativos, quando não há um diálogo crítico e reflexivo por parte das diferentes instâncias sobre as práticas avaliativas e seus resultados, principalmente quando a posição-sujeito de acatamento prevalece sobre a criticidade e as necessidades reais de mudança.

A partir dessas posições-sujeito, concluímos que há intervenções políticas e econômicas nas avaliações nacionais em larga escala aplicadas nos dias atuais e que essas intervenções refletem diretamente na dinâmica dos currículos, assim como na identidade e autoimagem das Instituições de Educação Superior.

\section{Referências}

AFONSO, A. J. Avaliação educacional: regulação e emancipação: para uma sociologia das políticas avaliativas contemporâneas. São Paulo: Cortez, 2000.

ALMEIDA JÚNIOR, V. de P. A avaliação da educação superior no contexto das Políticas Educacionais. In: DIAS SOBRINHO, J.; RISTOFF, D. I. Avaliação democrática: para uma Universidade Cidadã. Florianópolis: Insular, 2002. p. 165-184.

ARGENTINA. Ley de Educación Superior n. 24.521. Argentina, 1995.

BALL, S. J.; MAINARDES, J. (Orgs.). Políticas educacionais: questões e dilemas. São Paulo: Cortez, 2011.

BOGDAN, R.; BIKLEN, S. K. Investigação qualitativa em educação: uma introdução à teoria e aos métodos. Porto: Porto Ed., 1994.

BONAMINO, A.; SOUSA, S. Z. Três gerações de avaliação da educação básica no Brasil: interfaces com o currículo da/na escola. Educação e Pesquisa, São Paulo, v. 38, n. 2, p. 373388, abr./jun. 2012. DOI: 10.1590/S1517-97022012005000006 
BORDIGNON, N; CIMADON, A. O Sinaes: da concepção ao sepultamento: atos que afrontam o princípio da legalidade e a autonomia universitária. São Paulo: Conceito Editorial, 2012.

BRASIL. Ministério da Educação. Enade: apresentação. 2013. Disponível em: $<$ http: $/ /$ portal.mec.gov.br/index.php?Itemid $=313 \& i d=181 \& o p t i o n=$ com_content\&view $=$ articl e>. Acesso em: 18 out. 2015.

BRASIL. Lei de Diretrizes e Bases da Educação Nacional. Lei no 9.394, de 20 de dezembro de 1996. Disponível em: <http://www.planalto.gov.br/ccivil_03/leis/19394.htm>. Acesso em: 18 out. 2015.

BRASIL. Sistema Nacional de Avaliação da Educação Superior - SINAES. Lei no 10.861, de 14 de abril de 2004. Disponível em: < http://www.planalto.gov.br/ccivil_03/_ato20042006/2004/lei/110.861.htm>. Acesso em: 20 out. 2015.

BRASIL. Portaria Inep no 255, de 02 de junho de 2014. Divulga os componentes de Formação Geral e Específicos do ENADE 2014. Diário Oficial da União, Brasília, 04 de junho, 2014 Disponível em: <http://download.inep.gov.br/educacao_superior/enade/legislacao/2014/formacao_geral/for macao_geral_portaria_n_255_02_junho_2014.pdf>. Acesso em: 22 out. 2015.

BRASIL. Lei $\mathbf{n}^{\mathbf{0}}$ 9.131/95. Altera dispositivos da Lei no 4.024, de 20 de dezembro de 1961, e dá outras providências. Brasília: 24 de novembro de 1995. Disponível em: <http://www.planalto.gov.br/ccivil_03/leis/L9131.htm>. Acesso em: 20 out. 2015.

BRASIL. Lei $\mathbf{n}^{\mathbf{0}}$ 9.192/95. Altera dispositivos da Lei $\mathrm{n}^{\circ}$ 5.540, de 28 de novembro de 1968, que regulamentam o processo de escolha dos dirigentes universitários. Brasília, 21 de dezembro de 1995. Disponível em: <http://www.planalto.gov.br/ccivil_03/leis/L9192.htm>. Acesso em: 20 out. 2015.

BRITO, M. R. F. O SINAES e o ENADE: da concepção à implantação. Avaliação, Campinas; Sorocaba, v. 13, n. 3, p. 841-850, nov. 2008. DOI: 10.1590/S1414-40772008000300014

CALDERÓN, A. I.; POLTRONIERI, H.; BORGES, R. M. Os rankings na educação superior brasileira: políticas de governo ou de estado? Ensaio: Avaliação e Políticas Públicas em Educação, Rio de Janeiro, v. 19, n. 73, p. 813-826, out./dez. 2011. DOI: 10.1590/S010440362011000500005

DIAS SOBRINHO, J. Avaliação e transformações da Educação Superior brasileira (1995-2009): do provão ao SINAES. Avaliação: Revista da Avaliação da Educação Superior, Campinas; Sorocaba, v. 15, n. 1, p. 195-224, mar. 2010. DOI: 10.1590/S1414-40772010000100011

DIAS SOBRINHO, J. Avaliação: políticas educacionais e reformas da educação superior. São Paulo: Cortez, 2003.

DIAS SOBRINHO, J. Avaliação ética e política em função da educação como direito público ou como mercadoria? Educação e Sociedade, Campinas, v. 25, n. 88, p. 703-725, out. 2004. DOI: 10.1590/S0101-73302004000300004

DIAS SOBRINHO, J. Educação e avaliação: técnica e ética. In: DIAS SOBRINHO, J.; RISTOFF, D. I. Avaliação democrática: para uma universidade cidadã. Florianópolis: Insular, 2002. p. 37-68. 
As posições-sujeito (Estado e gestores) diante das avaliações em larga escala no Ensino Superior brasileiro

DIAS SOBRINHO, J. Avaliação educativa: produção de sentidos com valor de formação. Avaliação: Revista da Avaliação da Educação Superior, Campinas; Sorocaba, v. 13, n. 1, p. 193207, mar. 2008. DOI: 10.1590/S1414-40772008000100011

MACHADO, E. A. Avaliar é ser sujeito ou sujeitar-se? Mangualde: Edições Pedago, 2013.

ORLANDI, E. P. Discurso e texto: formulação e circulação dos sentidos. Campinas: Pontes, 2001.

PÊCHEUX, M. Semântica e discurso: uma crítica a afirmação do óbvio. Campinas: Ed. da UNICAMP, 1988. (Repertórios).

VASCONCELOS, M. L. M. C. Gestão e Qualidade do Ensino. In: COLOMBO, S. S.; CARDIM, P. A. G. (Orgs.). Nos bastidores da educação brasileira: a gestão vista por dentro. Porto Alegre: Artmed, 2010. p. 104-115.

WAITZ, I. R.; ARANTES, M. P. C. Avaliação do ensino superior e a prática docente. Anuário da Produção Acadêmica Docente, Valinhos, v. 3, n. 6, p. 249-262, 2009. 